\title{
Painful tic convulsif syndrome due to vertebrobasilar dolichoectasia
}

\author{
Puneet Mittal, Gaurav Mittal ${ }^{1}$ \\ Departments of Radiodiagnosis and ${ }^{1}$ Medicine, Punjab Institute of Medical Sciences, Jalandhar, Punjab, India.
}

\begin{abstract}
Combined clinical presentation of hemifacial spasm and ipsilateral trigeminal neuralgia is also known as painful tic convulsif (PTC). It is a rare condition and the most common cause is vascular compression. Vertebrobasilar dolichoectasia (VBD) is characterized by dilated and tortuous vertebral and basilar arteries. VBD is an uncommon and rarely reported cause of PTC. Magnetic resonance imaging (MRI), due to its inherent excellent contrast resolution, is an excellent modality for demonstrating the nerve compression by dilated and tortuous vessels seen in this condition. For this purpose, 3D MRI sequences are especially useful like constructive interference in steady state (CISS) and MR angiography. Both of these have been reported to be helpful in the diagnosis of this condition. We report a case of PTC in which we were able to document facial and trigeminal nerve compression by VBD on MRI, using CISS and time-of-flight MR angiography.
\end{abstract}

Key words: Hemifacial spasm, magnetic resonance, painful tic convulsif, vertebrobasilar dolichoectasia.

\section{Introduction}

Painful tic convulsif (PTC) is an uncommon condition with characteristic clinical presentation. It is most commonly caused by vascular compression. Vertebrobasilar dolichoectasia (VBD) is an uncommon cause of this condition, which can be readily diagnosed with magnetic resonance imaging which is also useful for demonstrating nerve compression.

\section{Case Report}

A 50-year-old male patient presented with 1 day history of left-sided facial pain and involuntary spasms of left side of the face involving perioral and periocular muscles. Physical examination was unremarkable except for involuntary movements. The patient was afebrile. There was no history of seizures or trauma in the past. There was no history of trigeminal neuralgia

\begin{tabular}{|l|l|}
\hline \multicolumn{2}{|c|}{ Access this article online } \\
\hline Quick Response Code: & Website: \\
\hline & www.ruralneuropractice.com \\
\cline { 2 - 2 } & \\
\hline
\end{tabular}

or hemifacial spasms in the past. There was no history of stroke. MRI with MR angiography was done on 1.5T scanner. Axial T2W images revealed dilated and tortuous vertebral and basilar arteries causing compression of left anterolateral aspect of pons. Axial time-of-flight (TOF) MR angiography images [Figure 1] and constructive interference in steady state (CISS) images [Figure 2] clearly demonstrated compression near exit zone of facial and trigeminal nerves, thus clinching the diagnosis of PTC. The patient was managed conservatively and no follow-up imaging was done.

\section{Discussion}

PTC is rare disorder characterized by simultaneous occurrence of trigeminal neuralgia and hemifacial spasms. This condition was first described by Cushing. ${ }^{[1]}$ A review of the literature shows about 47 case reports of this condition in the literature. ${ }^{[2,3]}$ The most common cause of this condition is vascular compression, usually by superior cerebellar artery or vertebral artery. VBD is an uncommon cause of simultaneous compression of facial and trigeminal nerves producing the characteristic manifestations. ${ }^{[3]} \mathrm{VBD}$ is of unknown pathogenesis but potentially serious condition, which is often underdiagnosed but can present with a variety of symptoms due to ischemic events and compressive symptoms. ${ }^{[4]}$

Address for correspondence:

Dr. Puneet Mittal, 448, Prem Basti, Sangrur (Pb.) - 148 001, India. E-mail: drpuneetmittal@gmail.com 

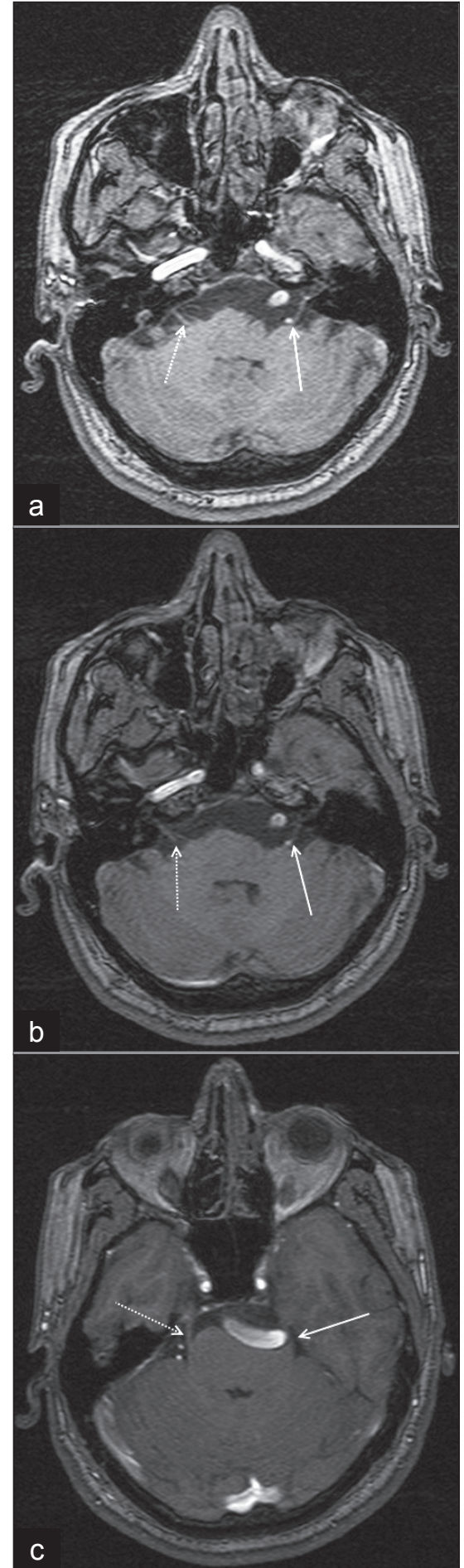

Figure 1: Axial time-of-flight MR angiography source images show compression of left facial nerve near its exit zone by left vertebral artery (white arrows in $a$ and $b$ ) and compression of left trigeminal nerve near its exit zone by basilar artery (white arrow in c). Normal course of facial nerve (dotted white arrows in a and b) and trigeminal nerve (dotted white arrow in c) is seen on the other side

Trigeminal nerve exits from the anterolateral aspect of pons as a large sensory and small motor root. It then travels in the prepontine cistern and then enters the Meckel's cave. Facial nerve exits from lateral margin of
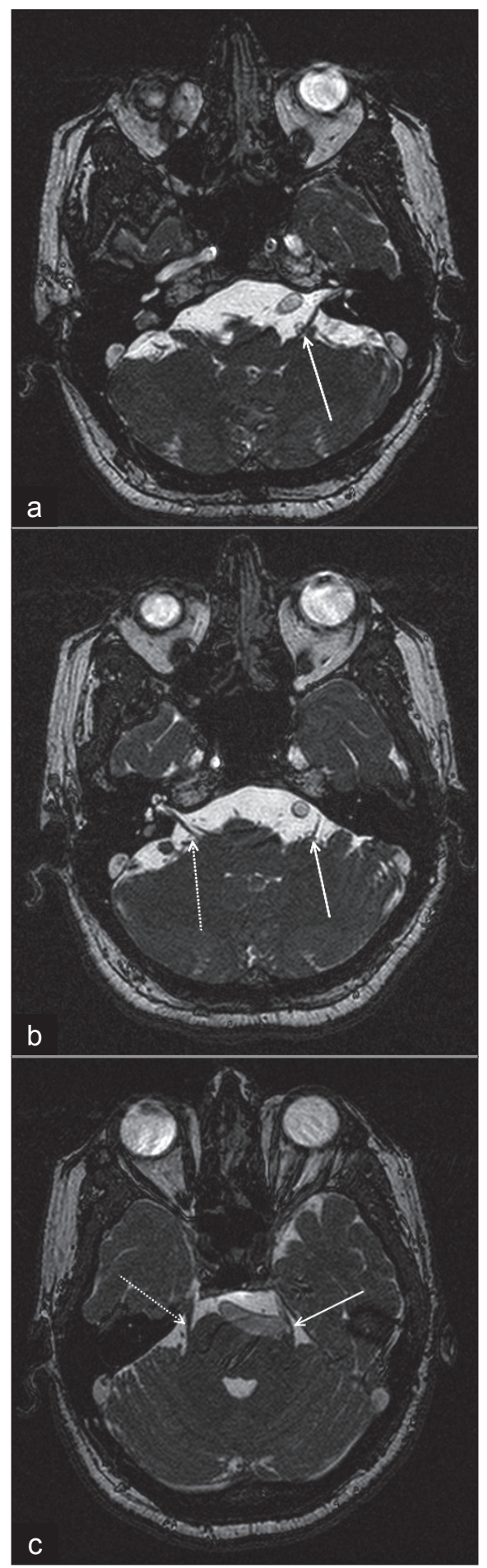

Figure 2: Axial constructive interference in steady state images again show compression and indentation of left facial nerve near its exit zone by left vertebral artery (white arrows in $a$ and $b$ ) and compression of left trigeminal nerve near its exit zone by basilar artery (white arrow in c). Normal course of facial nerve (dotted white arrow in b) and trigeminal nerve (dotted white arrow in c) is again seen

the inferior part of the pons and then enters the internal auditory canal. ${ }^{[3]}$

Compression of these nerves by dolichoectatic 
vertebrobasilar system is relatively rare and related to the diameter and tortuosity of these vessels. These patients are usually elderly hypertensives and there is left-sided predominance, as is seen in our case as well. ${ }^{[5]}$

MRI is an excellent modality for demonstrating vascular compression of facial and trigeminal nerves. Although VBD is adequately demonstrated on routine sequences, demonstration of nerve compression requires thinner sections. CISS is an excellent sequence for delineating these changes. ${ }^{[6]}$ It affords adequate contrast for visualizing the nerves against the background of bright cerebrospinal fluid, and vascular compression can be well demonstrated. Similarly, MR angiography also affords excellent visualization of the nerve compression.

In our case, we were able to demonstrate vascular compression of both facial and trigeminal nerves by ectatic vertebrobasilar system using TOF MR angiography and CISS sequences, thus helping to explain the symptomatology. PTC is a rare disorder. Vascular compression is its most common cause. MRI is excellent for demonstrating vascular compression, especially by employing thin sections.

A variety of medical treatments have been tried in the past, which include diphenylhydantoin, carbamazepine, ethanol injection of gasserian ganglion for trigeminal neuralgia, and saline neurolysis of facial nerve for hemifacial spasms. ${ }^{[7]}$ More recently, microsurgical decompression techniques have been successfully employed..$^{[8]}$

\section{References}

1. Cushing H. Major trigeminal neuralgia and their surgical treatment experiences with 332 Gasserian Operations: The Varieties of Facial Neuralgia. Am J Med Sci 1920;160:157-83.

2. Fonoff ET, Araújo VP, de Oliveira YS, Teixeira MJ. Neurovascular compression in painful tic convulsif. Acta Neurochir (Wien) 2009;151:989-93.

3. Aga P, Parashari U, Parihar A, Yadav R, Singh R, Kohli N. Simultaneous involvement of fifth and seventh nerves by vertebrobasilar dolichoectasia presenting as painful tic convulsif-demonstrated by MR imaging. Neurol India 2010;58:163-5.

4. Ubogu EE, Zaidat OO. Vertebrobasilar dolichoectasia diagnosed by magnetic resonance angiography and risk of stroke and death: A cohort study. J Neurol Neurosurg Psychiatry 2004;75:22-6.

5. Linskey ME, Jho HD, Jannetta PJ. Microvascular decompression for trigeminal neuralgia caused by vertebrobasilar compression. J Neurosurg 1994;81:1-9.

6. Yamakami I, Kobayashi E, Hirai S, Yamaura A. Preoperative assessment of trigeminal neuralgia and hemifacial spasm using constructive interference in steady state-three-dimensional Fourier transformation magnetic resonance imaging. Neurol Med Chir (Tokyo) 2000;40:545-56.

7. Pulsinelli WA, Rottenberg DA. Painful tic convulsif. J Neurol Neurosurg Psychiatry 1977;40:192-5.

8. Grigoryan YA, Goncharov MZ, Lazebny VV. Hemifacial spasm caused by a contralateral vertebral artery: Case report. Surg Neurol 2000;53:493-7.

Source of Support: Nil, Conflict of Interest: None declared. 